\title{
Probabilistic Rainfall Thresholds for Landslide Occurrences in Bhutan
}

\author{
Raju Sarkar, Abhirup Dikshit, Hemanta Hazarika, Koji Yamada, Krishna Subba
}

\begin{abstract}
Several works have been conducted all across the globe determining rainfall thresholds in context of intensity-duration thresholds. Such results provide results in terms of occurrence or non-occurrence of landslides. This paper determines probabilities for various rainfall parameters causing landslides using a Bayesian approach along Phuentsholing Thimphu Highway in Chukha Dzongkhag of Bhutan. For Bhutan Himalayas, probabilistic rainfall thresholds for landslide initiation has not yet been attempted. The probabilities determined can be used for early warning systems considering it is a major trade route with India.
\end{abstract} Bhutan.

\section{INTRODUCTION}

The most common and prominent natural hazard in Bhutan is landslides which are caused due to heavy monsoon precipitation and aggravated by anthropogenic activities. The infiltration during rainfall causes a change in groundwater conditions, soil parameters, antecedent moisture content (Wilson and Wieczorek 1995).

Such study is usually site specific due to variation in soil properties and the extensive data required for large areas are usually not available (Wieczorek and Guzzetti 2000; Capparelli and Versace 2011; De Luca and Versace 2017; Abdulhameed et al, 2018; Baum et al. 2002; Chen and Zhang 2014; Jahan et al, 2016). Empirical thresholds are determined by considering the daily rainfall data and landslide occurrences. The rainfall threshold relationship is fitted to an empirical equation $\mathrm{I}=\alpha \mathrm{D}^{-\beta}$ (Caine 1980). Several rainfall threshold equations have been derived for various regions all across the globe (Guzzetti et al. 2007; Aleotti 2004; Crosta and Frattini 2001; Cannon and Gartner 2005). Few works across Indian Himalayan region has

Revised Manuscript Received on September 25, 2019

* Correspondence Author

Raju Sarkar, Centre for Disaster Risk Reduction and Community Development Studies, Royal University of Bhutan, Rinchending, Bhutan. rajusarkar.cst@rub.edu.bt

Abhirup Dikshit, Centre for Disaster Risk Reduction and Community Development Studies, Royal University of Bhutan, Rinchending, Bhutan

Hemanta Hazarika, Japan International Cooperation Agency (JICA) Bhutan Office, Thimphu, Bhutan

Koji Yamada, Japan International Cooperation Agency (JICA), Bhutan Office, Thimphu, Bhutan.org

Krishna Subba, Japan International Cooperation Agency (JICA) Bhutan Office, Thimphu, Bhutan
Keywords : Probabilistic Thresholds, Chukha Dzongkhag,

also been conducted (Sengupta et al. 2010; Kanungo and Sharma 2014; Dikshit and Satyam 2018; González and Caetano 2017). The main concern with deterministic approach is that it provides single output, i.e, such methods lead to binary results i.e, either landslide occur or do not occur (Berti et al. 2012). The Bayesian approach overcomes such shortcomings and computes the probability of landslide occurrence concerning rainfall event characteristics. The process is easy, statistically meticulous, and returns a value of probability of landslide occurrence for various rainfall parameters considered. The Bayesian approach has been applied to Emilia-Romagna in Italy (Berti et al. 2012), Ha Giang region, Vietnam (Do and Yin 2018), Sierra Norte De Puebla, Mexico (González and Caetano 2017),

Kalimpong, India (Dikshit and Satyam 2017; Movahhed \& Omidvari, 2015). The results from the various case studies have validated the use of Bayesian approach.

\section{STUDYT AREA}

The Kingdom of Bhutan lies in the eastern section of the Himalayan area with an area of 38,394 sq. km. (Fig. 1). The nation is enclosed in all directions with Tibetan Plateau in the north and India surrounding the east, south and west with Arunachal Pradesh in east, Bengal and Assam in south, and the Darjeeling-Sikkim Himalayas in the west. The elevation of Bhutan varies from $100 \mathrm{~m}$ to $7500 \mathrm{~m}$ above sea level (a.s.1.) (Dunning et al. 2006) with elevation in Chukha region ranging from $1000 \mathrm{~m}$ to 4200 $\mathrm{m}$. The average daily traffic volume in the section is about 1,000 units to 2,000 units and is the second heaviest traffic by volume in the country (Japan International Cooperation Agency (JICA) 2014). The highway from Phuentsholing to Thimphu (capital city of Bhutan) often gets blocked by landslide debris, causing serious economic damage, given that this infrastructure links Bhutan to India which is the main link of trade and commerce for the country 


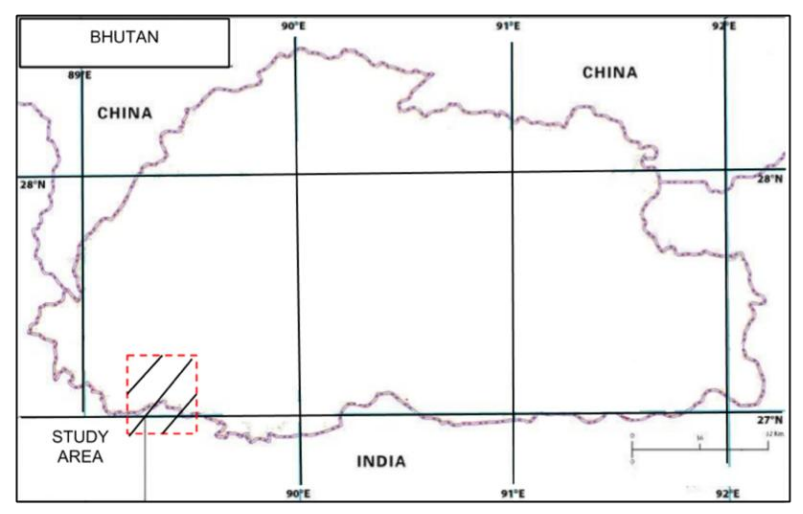

Fig. 1: Study Area, Source: Sarkar et al. 2019

The Chukha Dzongkhag is situated in the Lesser Himalayan region with $\mathrm{Om}$ Chhu river flowing from east to west. The annual rainfall in the region varies from $4000 \mathrm{~mm}$ to 6000 $\mathrm{mm}$ with rainfall reaching up to $800 \mathrm{~mm} /$ day during monsoons (Prokop and Walanus 2017).

The region has tectonically active sedimentary and metasedimentary rocks, gneiss, schist, quartzite, and limestone and is underlain mostly with schistose rocks. The soils in the region comprise of weaker phyllites which make the soil texture very fine and the slopes very unstable. These factors increase the frequency of landslides in the region causing massive destruction to life and property. Fig. 2 (a) and (b) represents the elevation map and LULC map of the Chukha Dzongkhag respectively.

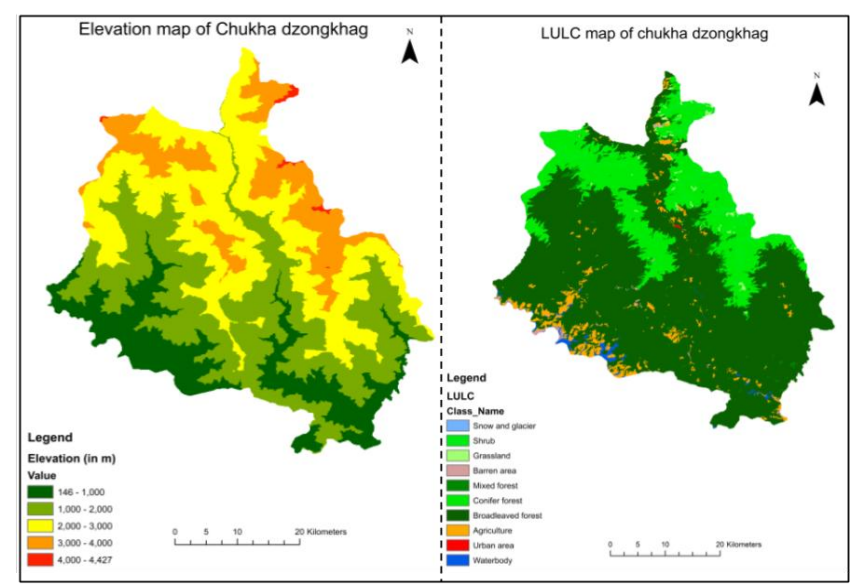

(a)

(b)

Fig. 2: (a) Elevation Map (b) LULC Map of Chukha

Dzongkha, Source: Sarkar et al. 2019

\section{CAUSES OF LANDSLIDES}

The heavy precipitation during the monsoons encourages rock weathering which results in an increase of erosion causing slope instability. The southern foothill of the Bhutan Himalayas is most susceptible to landslides as the region is steeper and the rocks beneath the soil are highly fractured permitting seepage. The situation is worsened by undermining of slopes by rivers during the monsoon period. Landslides in the region are frequently activated by toe cutting of the slope and blasting activities for various development activities. It is assumed that during the construction of the pavement the quality of material used is of standard quality. The increase in anthropogenic activities has escalated deforestation leading to slope instability. The most common form of the landslide can be attributed to the incessant precipitation during the monsoon season which leads to blocking of roads at major sections causing further damage to the region. Unplanned construction and poor land use planning often lead to the construction of homes on steep slopes, which increase household vulnerability to landslides.

The incidences of landslides affect the Phuentsholing-Thimphu Highway which is the major trade route connecting Bhutan and India (Kuensel 2017). Over 45 major slope disasters (JICA Expert Team for Project for Master Plan Study on Road Slope Management and the Department of Roads) have been widely reported especially during the monsoon along the highway and feeder roads leading to increased costs in repair and maintenance (Kuensel 2017). Landslides have an adverse effect on communication, forest density, dams. A large section of the Tsatichhu dam was damaged during July 2004 which lead to the release of massive volumes of water along with debris which damaged the paddy fields and the road connecting Mongar and Lhuntse (Dunning et al. 2006).

\section{DATAT CONSIDERED}

The average daily rainfall along with the cumulative rainfall with landslide occurrences is depicted in Fig. 3. A rainfall event is described as the total number of consecutive days of rainfall and the corresponding total rainfall $(\mathrm{mm})$ is divided by the rainfall duration (days) to provide the rainfall intensity $(\mathrm{mm} / \mathrm{day})$.
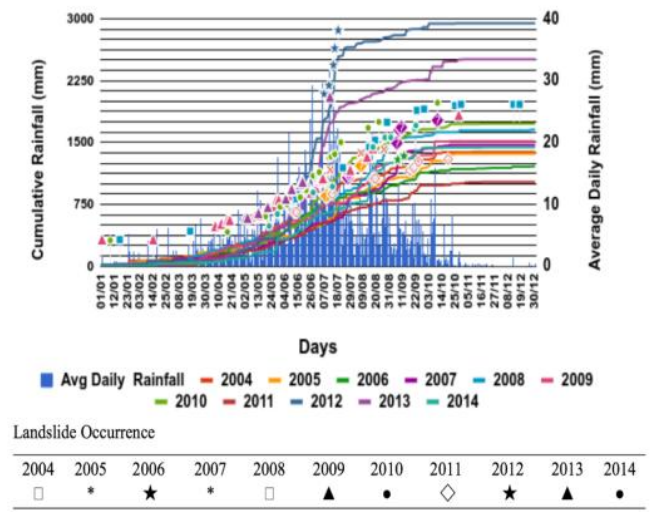

Fig. 3: Landslide and Rainfall Data for 2004-2014, Source: Sarkar et al. 2019

Published By: Blue Eyes Intelligence Engineering 


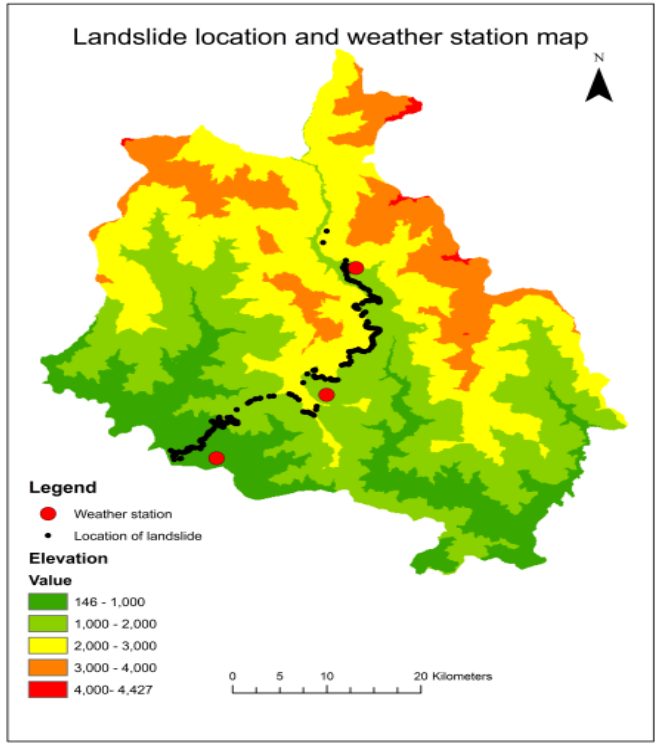

Fig. 4: Landslide locations and weather station map of Chukha Dzongkhag, Source: Sarkar et al., 2019

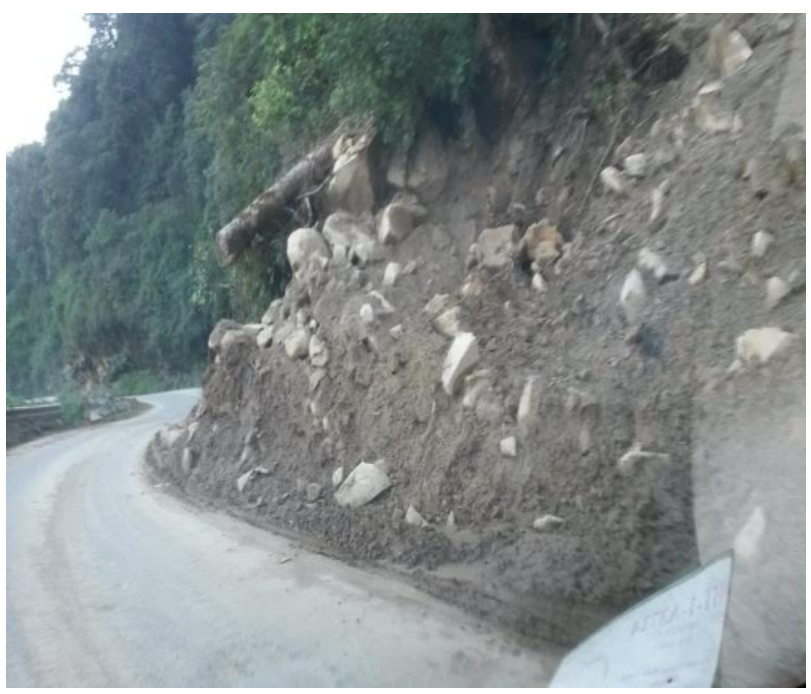

Fig. 5 Damage along the Phuentsholing-Thimphu Highway, Source: Sarkar et al. 2019

\section{BAYESIAN PROBABILITY}

Subsequently, precipitation alone cannot be the criteria for threshold precipitation instead a combination of numerous variables should be utilized (Berti et al. 2012). Therefore, if the output is not limited to either failure or no-failure condition as it is in the case of a deterministic approach. A full description of the approach briefly summarized here can be found in (Berti et al. 2012).

\section{RESULTS AND DISCUSSION}

Using the methodology explained above, one-dimensional Bayesian probability was determined for the three rain gauges (Chukha, Gedu and Malbase) situated in Chukha Dzongkhag. The results have been depicted in (Fig. 6[a-c] (i)-(vi)) for Chukha, Gedu and Malbase region respectively.

The maximum probability of landslide occurrence was 0.5 for a rainfall intensity of $80-90 \mathrm{~mm} /$ day and $90-100 \mathrm{~mm} /$ day for Chukha and Gedu respectively. However, Malbase had the highest probability of 0.333 for rainfall intensity of 70-80 $\mathrm{mm} /$ day. When considering rainfall duration, the maximum probability was 0.5 for 12 days for Chukha region, 0.5 for 10 as well as 11 days for Gedu region and 0.667 for 10 days for Malbase region. In context of event rainfall, the probability of landslides is maximum for $250-300 \mathrm{~mm}$ as well as $350-400 \mathrm{~mm}$ and 400-450 mm for Chukha region. In Gedu, the maximum probability of 0.333 was achieved for $300-350$ $\mathrm{mm}$ and $400-450 \mathrm{~mm}$. Malbase had the highest probability of 0.5 for $350-400 \mathrm{~mm}$.

In the present study, the number of rainfall events and landslide events in Chukha region for a rainfall intensity of $70-80 \mathrm{~mm} /$ day came out to be 2 and 1 respectively. Similarly, for event rainfall of $300-350 \mathrm{~mm}$ and $350-400 \mathrm{~mm}$ the number of rainfall events and landslide events were same which resulted the probability to be 1 . Similar observation can be observed for Malbase and Gedu regions.

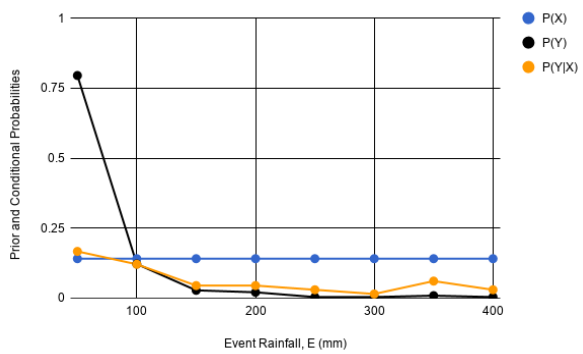

(i)

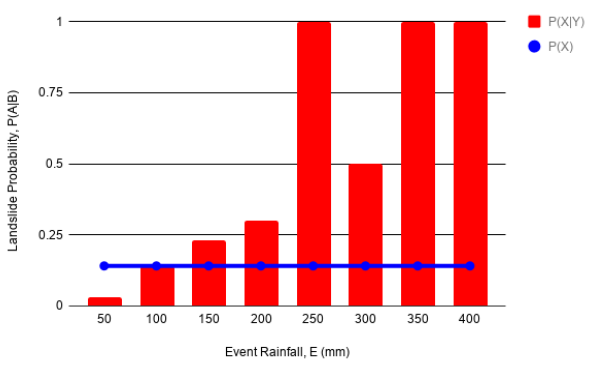

(ii)

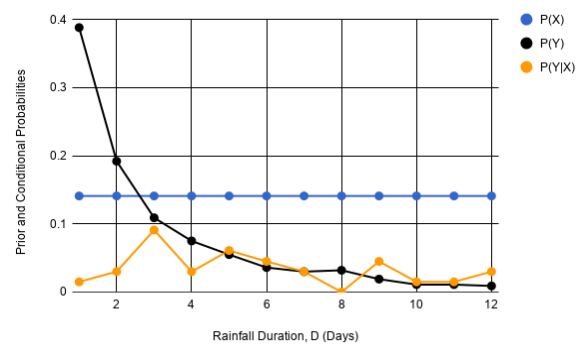

(iii)

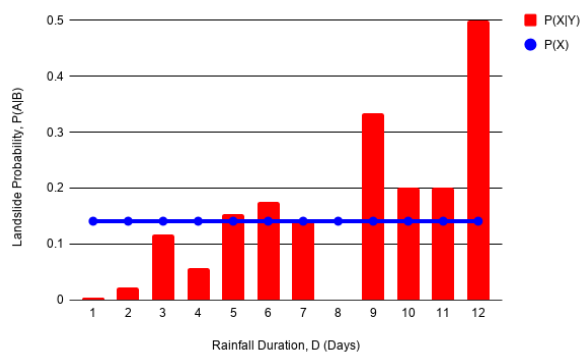

(iv) 
Probabilistic Rainfall Thresholds for Landslide Occurrences in Bhutan

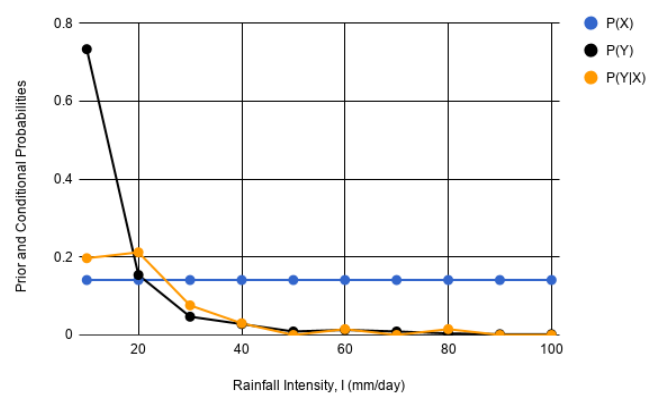

(v)

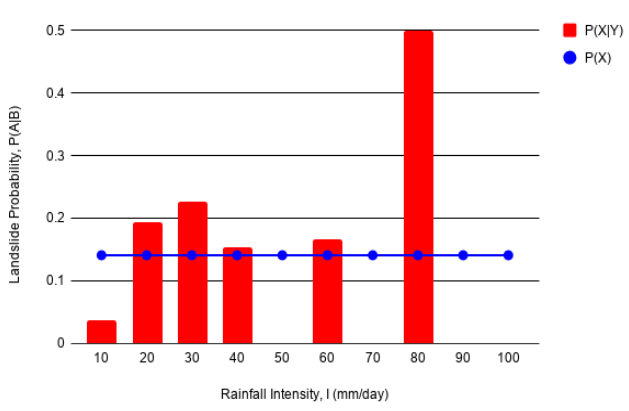

(vi)

Fig. 6(a) One-dimensional probability considering (i)-(ii) Event Rainfall (iii)-(iv) Rainfall Duration (v)-(vi) Rainfall Intensity for Chukha region, source: Sarkar et al. 2019

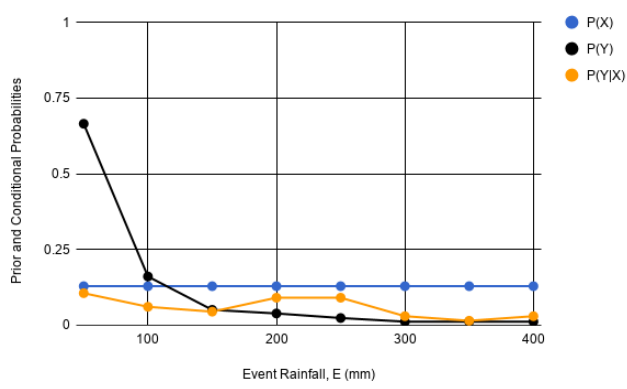

(i)

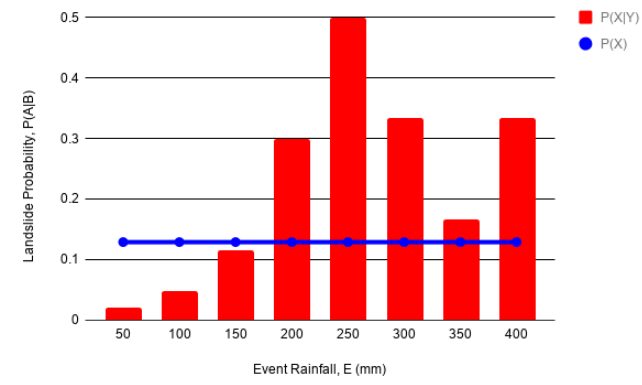

(ii)

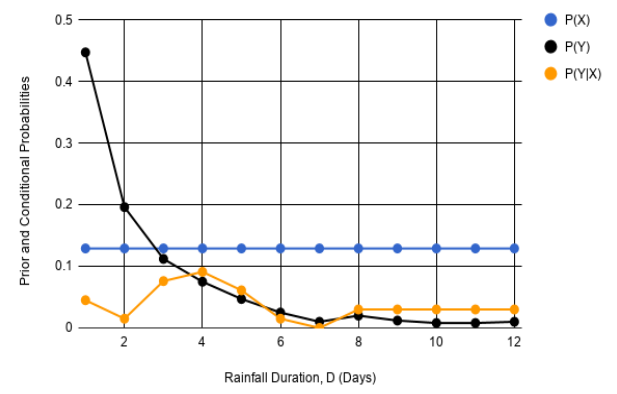

(iii)

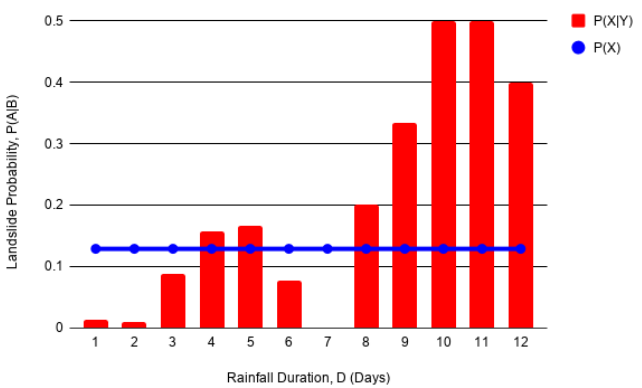

(iv)

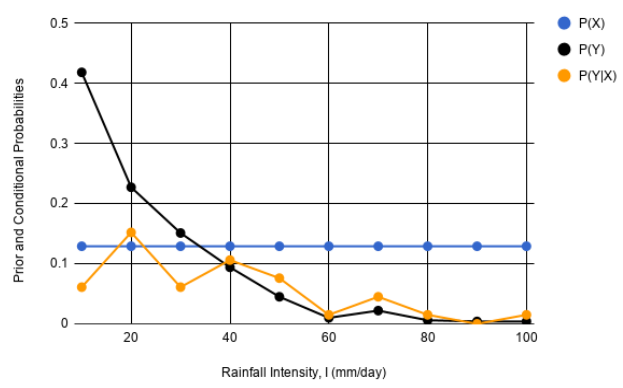

(v)

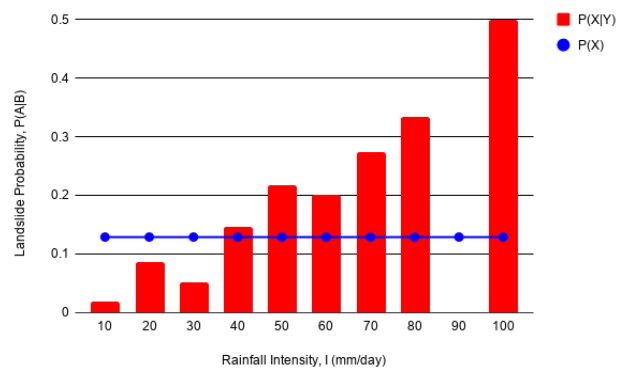

(vi)

Fig. 6(b) One-dimensional probability considering (i)-(ii) Event Rainfall (iii)-(iv) Rainfall Duration (v)-(vi) Rainfall Intensity for Gedu region, Source: Sarkar et al. 2019

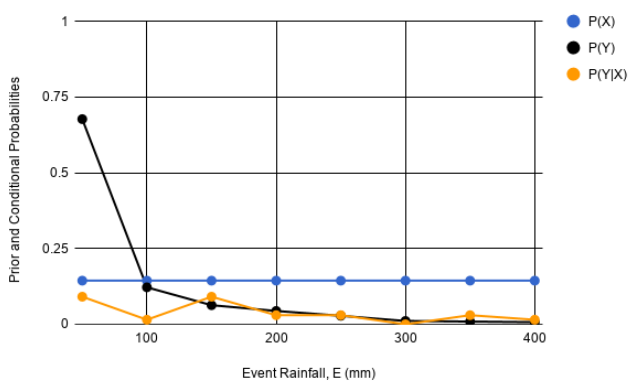

(i)

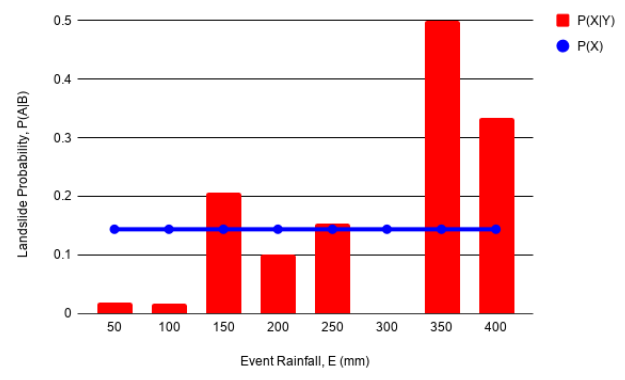

(ii) 


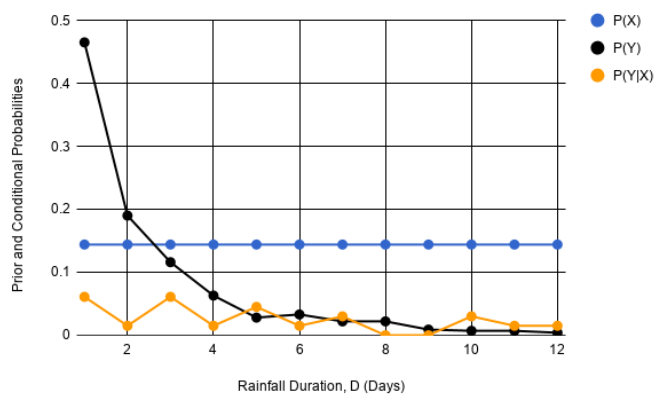

(iii)

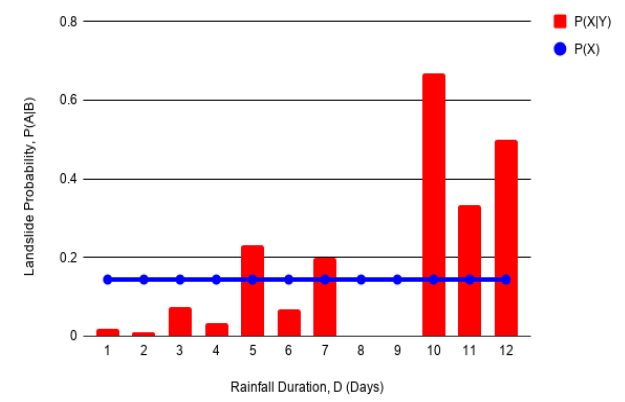

(iv)

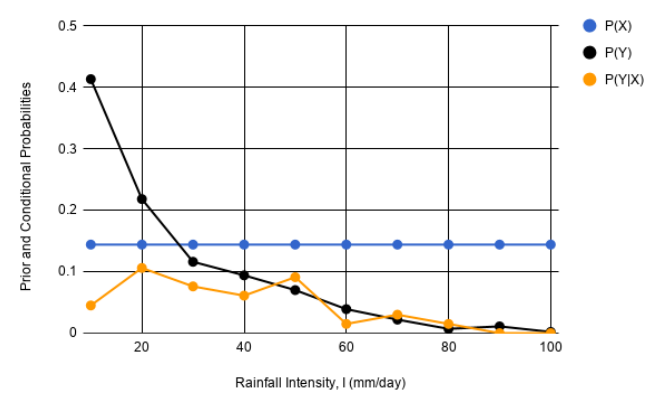

(v)

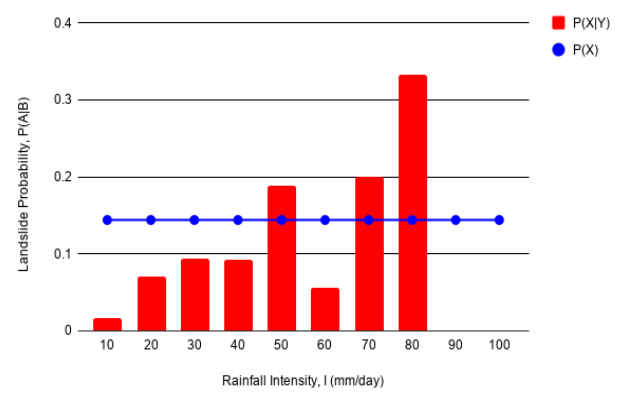

(vi)

Fig. 6(c) One-dimensional probability considering (i)-(ii) Event Rainfall (iii)-(iv) Rainfall Duration (v)-(vi) Rainfall Intensity for Malbase region, Source: Sarkar et al. 2019.

\section{BAYESIAN PROBABILITY FOR MULTIPLE RAIN GAUGES}

Apart from the determination of probabilities for a single rain gauge and a single rainfall parameter, it is imperative to compute the landslide probability of the entire region using a combination of rainfall parameters. Traditionally, Bayes theorem has been applied depending on the scale i.e., the area of the study region is divided by the number of rain gauges, and the corresponding area is termed as reference area (Berti et al. 2012). In this study, the region has been divided depending on the number of landslides which has occurred in proximity to a specific rain gauge. This means the probability caused under the influence of a single rain gauge is multiplied by the ratio of the number of landslides in the area by the total number of landslides. This assumption leads to a more realistic probabilistic calculation for the entire area. Fig. 7 illustrates the two-dimensional Bayesian probability considering all the rain gauges along and rainfall parameters of rainfall intensity and duration.

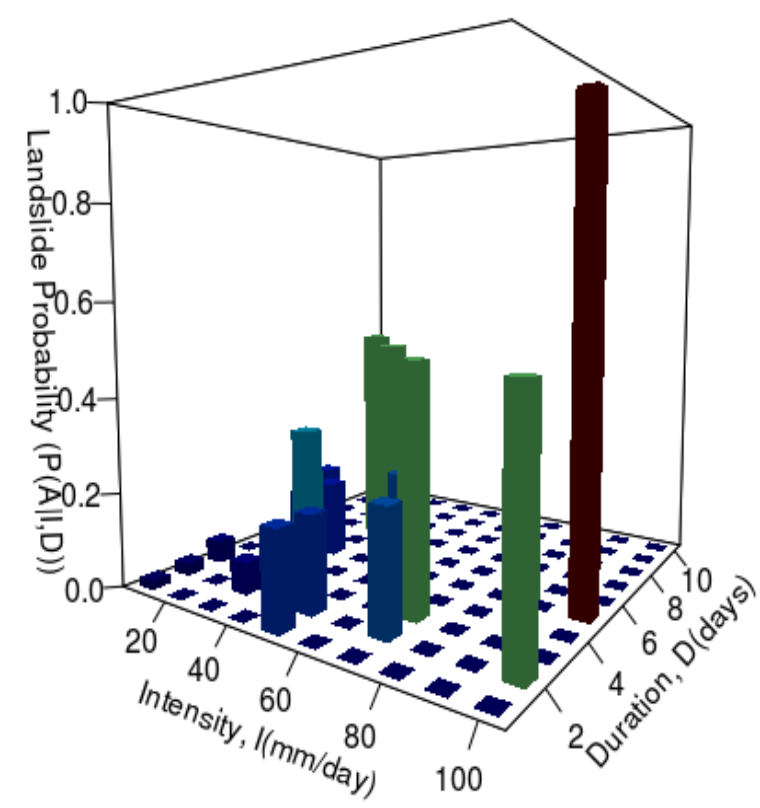

Fig. 7 Two-Dimensional Landslide Probability considering all the rainfall gauges, source: Sarkar et al. 2019

\section{CONCLUSIONS}

The analysis was carried out for Chukha Dzongkhag region of Bhutan which has a long history of landslide activity. The conclusions from the study are:

i) The study region has 3 rain gauges (Chukha, Gedu, Malbase) and the probabilities for areas affected due to each rain gauge concluded that Chukha region has high probability of landslide of 0.5 for rainfall intensity varying from $80-90 \mathrm{~mm} /$ day followed by Gedu with the same probability for intensity of 90-100 mm/day. However, on comparing for probabilities with rainfall duration the results signify that a longer duration of rainfall is required for landslides to occur in Chukha and Gedu as compared to Malbase.

ii) The two-dimensional Bayesian probability was computed for the entire Chukha Dzongkhag and the probabilities received highest probability of 0.333 for two cases: i) intensity of 60-70 $\mathrm{mm} /$ day and duration with 3 days ii) intensity of 20-30 mm/day and duration of 5 days.

iii) Bayesian probability method signifies the importance of probabilistic approach instead of deterministic methods as there are variations when using multiple parameters. Such differences are very critical for the early warning system as a small error can lead to disastrous results. 
This is a first of a kind analysis conducted for Bhutan Himalayan region and can be improved upon adding more variables and extensive rainfall and landslide data. Such analysis can be very helpful to develop a primitive early warning system which could save human lives.

\section{REFERENCES}

1. Abdulhameed, A. A., Al-Hamdi, K. E., \& Mathkoor, M. A. (2018), Clinical Evaluation of Efficacy and Safety of Combined Topical Timolol and Oral Propranolol in Children with Infantile Hemangioma. Journal of Clinical and Experimental Investigations, 9(1), 1-8.

2. Aleotti, P. 2004. "A warning system for rainfall-induced shallow failures". Eng Geol 73:247-265.

3. Baum, R.L., W.Z. Savage, J.W. Godt. 2002. "TRIGRS - a FORTRAN program for transient rainfall infiltration and grid-based regional slope stability analysis", US Geological Survey Open-File Report 2002-424.

4. Berti, M., M. L. V. Martina, S. Franceschini, S. Pignone, A. Simoni, M. Pizziolo. 2012. "Probabilistic rainfall thresholds for landslide occurrence using a Bayesian approach”. J. Geophys. Res. 117: F04006. doi:10.1029/2012JF002367.

5. Caine, N. 1980. "The rainfall intensity-duration control of shallow landslides and debris flows". Geogr Ann A 62: 23-27.

6. Cannon, S.H., and J.E. Gartner. 2005. "Wildfire-related debris flow from a hazards perspective". In: Debris flow hazards and related phenomena, edited by Jakob M., and Hungr O, 363-385. Berlin: Springer.

7. Capparelli, G., and P. Versace. 2011. "FLaIR and SUSHI: two mathematical models for early warning of landslides induced by rainfall". Landslides 8: 67. doi: 10.1007/s10346-010-0228-6.

8. Chen, H.X., and L.M. Zhang. 2014. "A physically-based distributed cell model for predicting regional rainfall-induced shallow slope failures". Engineering Geology 8: 67-79. doi: 10.1016/j.enggeo.2014.04.011.

9. Crosta, G.B., and P. Frattini. 2001. "Rainfall thresholds for triggering soil slips and debris flow". In Mediterranean storms, edited by Mugnai A., Guzzetti F., Roth G. Siena, 463-487. Proc. of the 2nd EGS Plinius Conf. on Mediterranean Storms. Siena, Italy.

10. De Luca, D.L., and P. Versace. 2017. "A comprehensive framework for empirical modeling of landslides induced by rainfall: The Generalized FLaIR Model (GFM)". Landslides 14: 1009. doi: 10.1007/s10346-016-0768-5.

11. Dikshit, A., and D.N. Satyam. 2018. "Estimation of rainfall thresholds for landslide occurrences in Kalimpong, India". Innov. Infrastruct. Solut 3: 24. doi: 10.1007/s41062-018-0132-9.

12. Dikshit, A., and N. Satyam. 2017. "Rainfall Thresholds for Landslide Occurrence in Kalimpong using Bayesian Approach" Indian Geotechnical Conference.

13. Do, H., and K. Yin. 2018. "Rainfall Threshold Analysis and Bayesian Probability Method for Landslide Initiation Based on Landslides and Rainfall Events in the Past”. Open Journal of Geology 8: 674-696. doi: 10.4236/ojg.2018.87040.

14. Dunning, S.A., N.J. Rosser, D.N. Petley, C.R. Massey. 2006. "Formation and failure of the Tsatichhu landslide dam, Bhutan". Landslides 3: 107. doi:10.1007/s10346-005-0032-x.

15. Dunning, S., C. Massey, N. Rosser. 2009. "Structural and geomorphological features of landslides in the Bhutan Himalaya derived from terrestrial laser scanning". Geomorphology 103:17-29.

16. Gansser, A. 1983. Geology of the Bhutan Himalaya. Basel, Switzerland: Birkhaüser Verlag.

17. González, A., and E. Caetano. 2017. "Probabilistic Rainfall Thresholds for Landslide Episodes in the Sierra Norte De Puebla, Mexico". Natural Resources 8: 254-267. doi: 10.4236/nr.2017.83014

\section{AUTHORS PROFILE}

Raju Sarkar: Professor and Head, Centre for Disaster Risk Reduction and Community Development Studies, Royal University of Bhutan, Rinchending, Bhutan

Abhirup Dikshit: Visiting Researcher, Centre for Disaster Risk Reduction and Community Development Studies, Royal University of Bhutan, Rinchending, Bhutan

Hemanta Hazarika: Professor, School of Interdisciplinary Science and Innovation, Kyushu University, Fukuoka, Japan
Koji Yamada: Chief Representative, Japan International Cooperation Agency (JICA), Bhutan Office, Thimphu, Bhutan

Krishna Subba: Senior Programme Officer, Japan International Cooperation Agency (JICA) Bhutan Office, Thimphu, Bhutan 